\title{
Involvement of fission yeast Pdc2 in RNA degradation and P-body function
}

\author{
CHUN-YU WANG, ${ }^{1}$ YI-TING WANG, ${ }^{1}$ WAN-YI HSIAO, and SHAO-WIN WANG \\ Institute of Molecular and Genomic Medicine, National Health Research Institutes, Miaoli County 350, Taiwan, Republic of China
}

\begin{abstract}
In this study we identified Pdc2, the fission yeast ortholog of human Pat1b protein, which forms a complex with Lsm1-7 and plays a role in coupling deadenylation and decapping. The involvement of Pdc2 in RNA degradation and P-body function was also determined. We found that Pdc2 interacts with Dcp2 and is required for decapping in vivo. Although not absolutely essential for P-body assembly, overexpression of Pdc2 enhanced P-body formation even in the absence of Pdc1, the fission yeast functional homolog of human Edc4 protein, indicating that Pdc2 also plays a role in P-body formation. Intriguingly, in the absence of Pdc2, Lsm1 was found to accumulate in the nucleus, suggesting that Pdc2 shuttling between nucleus and cytoplasm plays a role in decreasing the nuclear concentration of Lsm1 to increase Lsm1 in the cytoplasm. Furthermore, unlike other components of P-bodies, the deadenylase $\mathrm{Ccr} 4$ did not accumulate in P-bodies in cells growing under favorable conditions and was only recruited to P-bodies after deprivation of glucose in a Pdc2-Lsm1-dependent manner, indicating a function of Pdc2 in cellular response to environmental stress. In supporting this idea, pdc2 mutants are defective in recovery from glucose starvation with a much longer time to re-enter the cell cycle. In keeping with the notion that Pat1 is a nucleocytoplasmic protein, functioning also in the nucleus, we found that Pdc2 physically and genetically interacts with the nuclear $5^{\prime}-3^{\prime}$ exonuclease Dhp1. A function of Pdc2-Lsm1, in concert with Dhp1, regulating RNA by promoting its decapping/destruction in the nucleus was suggested.
\end{abstract}

Keywords: fission yeast; P-bodies; decapping

\section{INTRODUCTION}

Cytoplasmic processing bodies (P-bodies) are dynamic RNA protein aggregates that play critical roles in mRNA degradation, nonsense-mediated mRNA decay (NMD), translational repression, and RNA-mediated gene silencing (Eulalio et al. 2007a). Because several components of P-bodies, such as the decapping enzyme and its coactivators, are found in both yeast and mammalian cells, it is believed that P-bodies are evolutionarily conserved among eukaryotes. The decapping of mRNAs, which occurs inside P-bodies, represents a critical step in mRNA turnover and is therefore tightly regulated. In yeast, the catalytic subunit of decapping enzyme Dcp2 interacts directly with its cofactor Dcp1 (She et al. 2006). This complex has low intrinsic decapping activity and requires additional proteins for full activity, including the enhancer of decapping 1-3 (Edc1-3), the heptameric Lsm1-7 complex, the DExH/D-box RNA helicase 1 (Dhh1, RCK/p54 in mammals), and Pat1. All of these proteins colocalize to P-bodies and may activate decapping by different mechanisms (Nissan et al. 2010).

\footnotetext{
${ }^{1}$ These authors contributed equally to this work. Corresponding author: shaowinwang@nhri.org.tw Article is online at http://www.rnajournal.org/cgi/doi/10.1261/rna.059766. 116.
}

In metazoans, Dcp1 and Dcp2 form direct but weak interactions that are facilitated by the decapping activator Edc4 (also known as Ge-1 or Hedls, human enhancer of decapping large subunit) (Chang et al. 2014). Edc4 is required for Dcp1Dcp2 catalytic activity (Fenger-Gron et al. 2005), which is not present in Saccharomyces cerevisiae, indicating that species diversity has developed. The different protein composition of P-bodies between different species was highlighted by our recent study with the identification of the fission yeast $\mathrm{Pdcl}$ (partner of decapping enzyme protein 1) as the functional homolog of Edc4 (Wang et al. 2013), a third component of the decapping enzymes that is thought to be absent from fungi. Pdc1 forms a complex with Dcp2. Similar to Edc4, Pdc1 is an enhancer of decapping and plays a vital role in the formation of P-bodies. The protein composition and structure organization of fission yeast P-bodies is therefore more closely related to high eukaryotes than that of S. cerevisiae. Cross-species studies of this sort may provide useful information in understanding the evolutionary path of these protein complexes.

(C) 2017 Wang et al. This article is distributed exclusively by the RNA Society for the first 12 months after the full-issue publication date (see http:// rnajournal.cshlp.org/site/misc/terms.xhtml). After 12 months, it is available under a Creative Commons License (Attribution-NonCommercial 4.0 International), as described at http://creativecommons.org/licenses/by-nc/4.0/. 
To gain more insight into the difference of P-body components in regulating RNA degradation in different organisms, in the present study we describe the characterization of Pdc2, the fission yeast ortholog of the Pat1 protein, identified in the same study. Similar to Pdc1/Edc4, Patl proteins have been proposed to act as scaffold proteins that interact with mRNA and multiple protein factors involved in mRNA decay (Marnef and Standart 2010). In S. cerevisiae, in addition to mRNA degradation, a function of Pat1 in translation repression has been previously described (Nissan et al. 2010). Intriguingly, as in the case of Pdcl, we found that the role of Pdc2 is similar to the Pat1 homolog of human but not S. cerevisiae, which appears to be involved only in mRNA degradation. Consistent with the function in mRNA decay, Pdc2 interacts with Dcp2 localized to P-bodies and is required for decapping in vivo. Although not absolutely essential for P-body assembly, similar to Pdc1 (Wang et al. 2013), Pdc2 has the potential to be self-associated, which may facilitate P-body formation.

In addition to its multiple regulatory roles in the cytoplasm, several lines of evidence suggested that Pat 1 is a nucleo-cytoplasmic shuttling protein (Teixeira and Parker 2007) and may have a nuclear role that remains to be clarified. In keeping with this notion and consistent with the proposed role of Pat 1 in coupling deadenylation and decapping, in the absence of Pdc2, Lsm1 was found to accumulate in the nucleus, and the recruitment of deadenylase Ccr4 to P-bodies in the absence of glucose was defective. Furthermore, we found that Pdc2 interacts with the nuclear $5^{\prime}-3^{\prime}$ exonuclease Dhp1, the ortholog of budding yeast Rat1 protein, and may function together with the decapping enzyme Dcp1-Dcp2 to regulate long-noncoding RNA (lncRNA) in the nucleus.

\section{RESULTS}

\section{Pdc2 as a novel component of fission yeast P-body}

To gain more insight into the molecular mechanism of P-body assembly in $S$. pombe, tandem affinity purification was performed to identify proteins associated with Dcp2. The two-step immunoglobulin G (IgG)-Sepharose and calmodulin resin affinity purification was carried out on $10-\mathrm{L}$ cultures of the Dcp2-TAP strain, as described previously (Wang et al. 2013). The protein composition of the TAP complex was examined directly by silver staining, and their identities were determined by MALDI MS/MS analysis (Fig. 1B). In addition to $\mathrm{Pdc1}$, a single peptide previously masked by the Dcp2 fragments corresponding to an uncharacterized, nonessential protein encoded by the chromosomal locus SPBC19G7.10c, the ortholog of Pat1 protein (Fig. 1A), was identified. In deference to the existing gene name of Pat1 for Ran1 serine/threonine protein kinase in Schizosaccharomyces pombe GeneDB and in keeping with our previous study (Wang et al. 2013), we refer to this gene as partner of decapping enzyme protein 2 (Pdc2). Given the involvement of Pat1 in translational repression and mRNA decay in other organisms (Marnef and Standart 2010), the gene identified was subject to further analysis for its involvement in related functions.

To determine whether or not Pdc2, like Pat1, is a component of the fission yeast P-bodies, targeted recombination was used to generate GFP-fusion protein in its normal chromosomal context under the control of the endogenous promoter, expressing the full-length protein C-terminally tagged with GFP. Examination of living cells by fluorescence microscopy reveals accumulation of Pdc2-GFP fusion proteins in cytoplasmic foci (Fig. 1C), whereas control GFP protein was distributed evenly throughout the cells with a slight enrichment in the nucleus (right panel). As the characteristic feature of the components of P-bodies, these signals overlapped with the decapping enzyme Dcp2 (Fig. 1C), which can be further enhanced by deprivation of glucose (Fig. 1D). In keeping with the vital role of Pdc1 in P-body formation, we observed that $p d c 1$ mutants showed a strong reduction in the accumulation of Pdc2 into microscopically visible P-bodies, although some P-bodies could still form during glucose starvation (Fig. 1D, right panel).

The results described above demonstrated that Pdc2 as a novel component of the fission yeast P-body interacts with Dcp2. The interaction was further extended to other components of P-bodies including Edc3, Exo2, Pdc1, and Ste13, which can be readily demonstrated by coimmunoprecipitation (Fig. 1E). The interaction is specific between Pdc2 and components of P-bodies, as no interaction was detected with control GFP protein alone. Similarly to human Pat1b proteins (Braun et al. 2010), deletion of the C-terminal region of Pdc2 (residues 499-754) affected the interaction with decapping factors, at least for Edc3 and Pdc1 (for the other proteins the bait concentration decreased in the pulldown) (Fig. 1E). In line with these results, a strong reduction in the accumulation of the truncated Pdc2 proteins in the microscopically visible P-bodies was observed (Fig. 1D). Taken together, these results suggested that Pdc2, like Pat1, is a component of the fission yeast P-bodies.

During the analysis of the interaction among the components of P-bodies and Pdc2 mutant proteins, we consistently observed reduction of the protein levels of these components such as Dcp2, Exo2, and Ste13 from immunoprecipitation in the $p d c 2$ mutation genetic background, which is most evident in the case of Dcp2 proteins (Fig. 1E), suggesting that Pdc2 may affect their protein stability. A recent report has presented evidence that in human cells, in the absence of Edc4 association, uncomplexed Dcp2 proteins were targeted for ubiquitin-mediated proteasomal degradation (Erickson et al. 2015). Pdc2 may function in a similar manner to ensure correct complex stoichiometry by targeting Dcp2 as well as other components of P-bodies. In supporting this idea, we found that Dcp2 was normally subjected to the regulation of ubiquitin-mediated proteasomal degradation and was stabilized in the $m t s 2$ mutant proteases (Fig. 1F). In the absence 
A
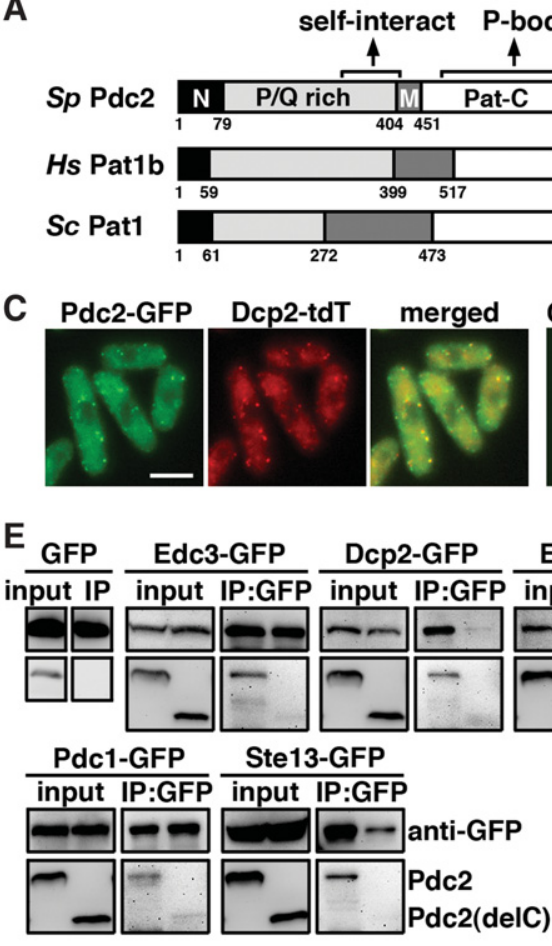

Dcp2-tdT
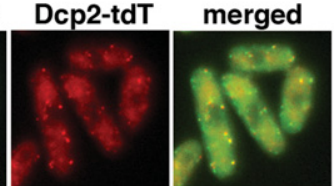

self-interact P-body

\begin{tabular}{|c|c|c|c|}
\hline $\mathbf{N}$ & $\mathrm{P} / \mathrm{Q}$ rich & $\mathbf{M}$ & Pat-C \\
\hline
\end{tabular}
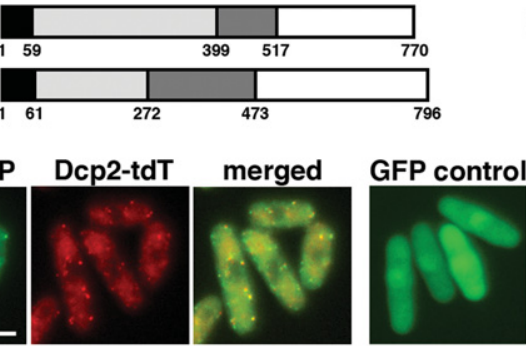

Exo2-GFP input IP:GFP
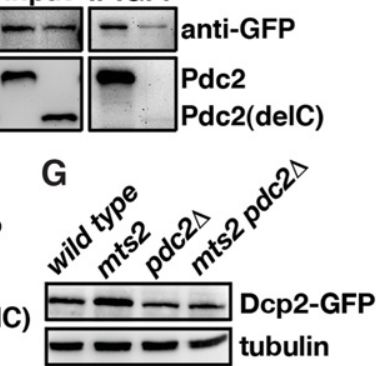

1.01 .50 .60 .6 fold change $(n=2)$
B

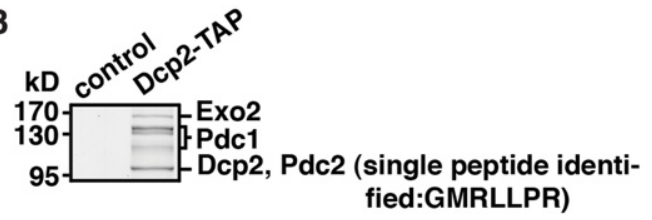

D Pdc2-GFP Pdc2(delC) Pdc2-GFP

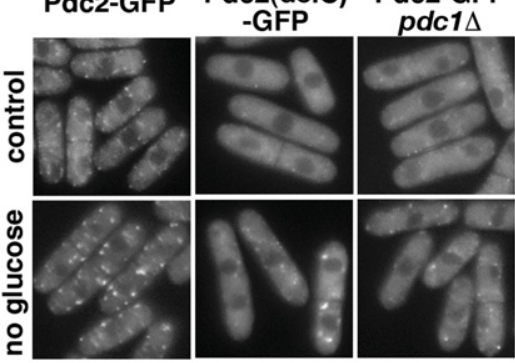

FIGURE 1. Pdc2 is a component of the fission yeast P-bodies. (A) Schematic representation of the domain structures of Pdc2 with regions required for the interactions identified in this study indicated. (B) Tandem affinity purification (TAP)-tag pull-down of Dcp2 proteins resolved by SDS-PAGE was visualized by silver staining. Identity of constituent proteins (identified by MALDI MS/MS analysis of individual bands) is indicated on the right. (C) Merged images of fluorescence micrographs showing GFP-fusion proteins of Pdc2 (green) and Dcp2-tdTomato (red) localization in living cells grown at $30^{\circ} \mathrm{C}$. Bar, $5 \mu \mathrm{m}$. (D) Fluorescence micrographs of strains expressing full-length or C-terminal truncated (delC) Pdc2 GFP-fusion proteins in wild-type cells or $p d c 1 \Delta$ mutants grown at $30^{\circ} \mathrm{C}$ (control), or after deprivation of glucose for $15 \mathrm{~min}$. (E) Coimmunoprecipitation was performed with extracts from strains with indicated proteins tagged with GFP also expressing full-length or truncated Pdc2-Flag proteins. GFP-trap affinity resin was used to pull down GFP fusion proteins. Immunoprecipitates were then analyzed by Western blotting using antibodies against GFP and Flag. $(F)$ Coimmunoprecipitation was performed with extracts from wild-type cells, and $m t s 2$ mutants expressing Pdc2-HA proteins were then analyzed by Western blotting using antibodies against ubiquitin (ubi) and HA to reveal Pdc2. Antibody against a-tubulin was used as the control. ( $G$ ) Wholecell protein extracts of the strains indicated were prepared by alkaline extraction followed by trichloroacetic acid precipitation. The extracts were separated by SDS-PAGE and subjected to immunoblotting using anti-GFP antibodies to reveal Dcp2 proteins. Antibody against $\alpha$-tubulin was used as the control. The relative level of Dcp2 protein is indicated beneath each lane (average of two independent experiments).

of Pdc2, this level of regulation was compromised and Pdc2 failed to accumulate in the $m t s 2$ mutant (Fig. 1G).

\section{Roles of Pdc2 in mRNA decay}

Given the close interaction between Pdc2 and Dcp2, we tested whether Pdc2 plays a role in decapping in vivo. Splinted ligation followed by the RT-PCR method (Fig. 2A) was used to detect the products of decapped rps 23 mRNA as previously described in wild-type cells and $p d c 2$ mutants (Wang et al. 2013). As shown in Figure 2B, decapped products of $r p s 23$ mRNA were detected in wild-type cells, which were reduced in $p d c 2$ mutants, as well as in $p d c 1$ mutants where mRNA decapping is affected. Despite the lack of detectable decapped rps 23 mRNA in pdc2 mutants, no substantial increase of rps 23 mRNA was observed, suggesting that the contribution of Pdc2-dependent decapping to rps 23 mRNA turnover is quite minor. As a positive control, removal of the $5^{\prime}$ cap of mRNA in vitro by tobacco acid pyrophosphatase (TAP) resulted in the detection of RT-PCR products in both $p d c 1$ and $p d c 2$ mutants (right panel). We concluded that Pdc2 is an enhancer of decapping.

Both human Pat $1 \mathrm{~b}$ and Drosophila HPat trigger decapping as well as deadenylation when tethered to mRNAs (Haas et al. 2010; Ozgur et al. 2010). However, in S. cerevisiae, neither Pat1 nor Lsm1 seems to affect deadenylation (Hatfield et al. 1996). To explore whether Pdc2 would affect deadenylation in vivo, we examined the $3^{\prime}$ end of the rps 23 mRNA using a RACE-PAT assay (Fig. 2A, right panel; Win et al. 2006). As shown in Figure 2C, distinct products with the lengths consistent with polyadenylation in the region of the mature $r p s 23$ mRNA $3^{\prime}$ end were observed in wild-type cells. The lengths of these products were very similar in $p d c 2$ mutants and were further verified by sequencing after the TOPO 
A Splinted ligation RT-PCR PCR poly(A) test

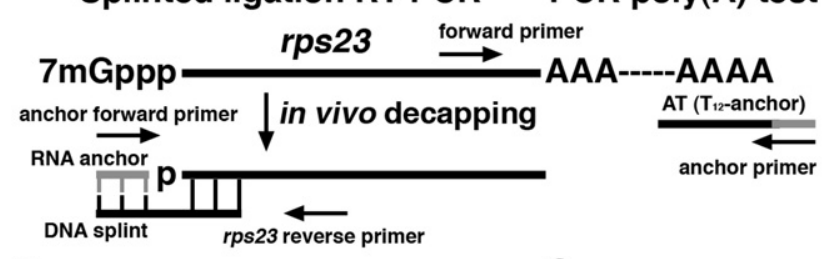

B

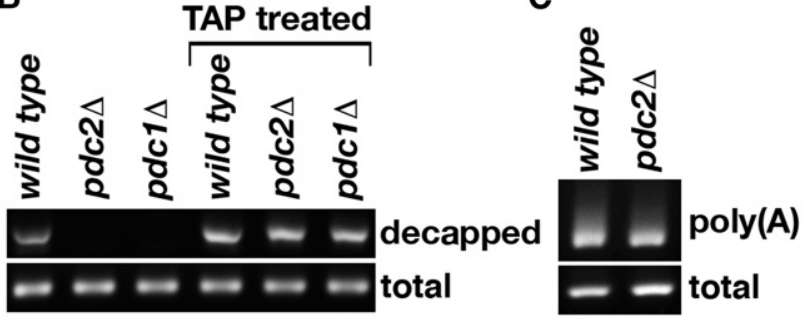

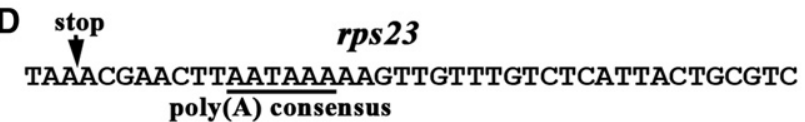

1. TAAACGAACTTAATAAAAAGTTGTTTGTCTCATTAAAA--AА

2. TAAACGAACTTAATAAAAAGTTGTTTGTCTCAT--AAA--AA

3. TAAACGAACTTAATAAAAAGTTGTTTGTCTCA---AAA--AA

4. TAAACGAACTTAATAAAAAGTTGTTTGTC------AАA--AA

$\operatorname{pdc}^{+} \quad 17 \pm 5(\overline{12-30)}$

pdc2 $216 \pm 6 \quad(12-27)$

20 clones each from 2 repeat

FIGURE 2. Pdc2 is required for mRNA decapping in vivo. $(A)$ Schematic representation of the splinted ligation and PCR poly $(\mathrm{A})$ assay for detection of decapped mRNA and estimation of the poly(A) length. (B) Splinted ligation RT-PCR was used to detect endogenous decapped $r p s 23 \mathrm{mRNA}$ present in $10 \mu \mathrm{g}$ of total RNA isolated from $p d c 2$. As a positive control, total RNA was treated with tobacco acid pyrophosphatase (TAP) to remove the $5^{\prime}$ cap indicated on the right. $(C)$ Total RNA from cultures of wild-type cells and $p d c 2$ mutants was subject to RACE-PAT assay as in panel $A$. RT-PCR products were separated on a $\%$ agarose gel. $(D)$ The $3^{\prime}$-terminal sequences of cloned reverse transcription products. The average lengths of $r p s 23 \mathrm{mRNA}$ poly(A) tails of 20 randomly selected clones in wild-type cells and $p d c 2$ mutants were indicated.

cloning (Fig. 2D). Of the 20 randomly selected clones in two repeats, the average lengths of $r p s 23 \mathrm{mRNA}$ poly(A) tails were 17 and 16 in wild-type cells and $p d c 2$ mutants, respectively. We concluded that Pdc2 does not affect deadenylation, at least for the analyzed gene.

In S. cerevisiae, overexpression of Pat1 or Scd6 repressed translation, leading to growth inhibition (Nissan et al. 2010). It has been suggested that, in addition to facilitating decapping, S. cerevisiae Pat1 seems to play additional roles at earlier steps involving translational repression and mRNA rearrangement that set the stage for decapping. Translational repression activity has also been noted for Patl homologs of Xenopus but not human (Marnef and Standart 2010; Ozgur et al. 2010). To determine whether Pdc2 would play a role in translational repression, we examined the effect of Pdc2 overexpression on cell growth. Targeted homologous recombination was used to replace the endogenous $p d c 2^{+}$ promoter with the thiamine-repressive $n m t 1$ promoter, at the same time introducing an HA epitope tag sequence fused in-frame to the $5^{\prime}$ end of the $p d c 2$ open reading frame. Removal of thiamine from the medium led to an elevated level of Pdc2 (OP) in comparison with the level driven by its own promoter (control) (Fig. 3B). As shown in Figure 3A, this level of Pdc2 overexpression (Pdc2-OP) did not lead to growth inhibition. Similarly, overexpression of Sum2, the fission yeast ortholog of Scd6, did not inhibit cell growth (Sum2-OP). To directly examine the effect of Pdc2 on translation, we measured the polyribosome profiles but could not observe significant changes when Pdc2 overexpressed (Fig. 3C). As a positive control, puromycin was added to repress

A

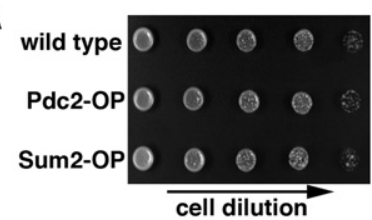

B

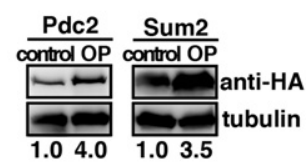

C

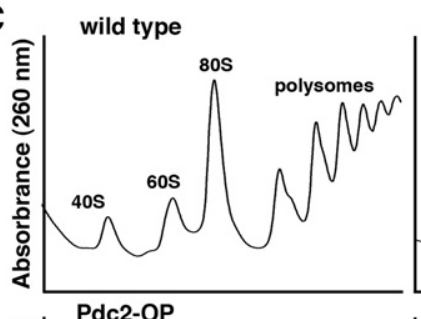

wild type + puromycin
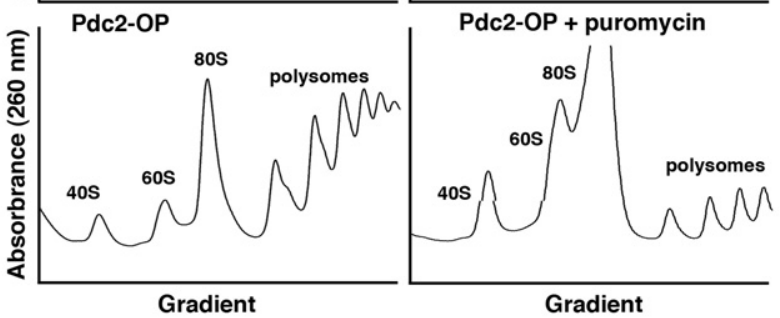

D

Roles of Pat1 proteins in different species

\begin{tabular}{lccc}
\hline & $\begin{array}{c}\text { Translation } \\
\text { Repression }\end{array}$ & Decapping & Deadenylation \\
\hline Sc pat1 & + & + & - \\
Sp pdc2 & - & + & - \\
Hs Pat1b & - & + & + \\
\hline
\end{tabular}

FIGURE 3. Overexpression of Pdc2 does not repress translation. $(A)$ Tenfold serial dilutions of the indicated strains spanning the range of $10^{2}-10^{6}$ cells were spotted onto a YE-agar plate and photographed after $2 \mathrm{~d}$ incubation at $30^{\circ} \mathrm{C}$. $(B)$ Whole-cell protein extracts from wild-type cells overexpressing Pdc2 or Sum 2 from the $n m t 1$ promoter $(\mathrm{OP})$ were prepared by alkaline extraction, followed by trichloroacetic acid precipitation. The extracts were separated by SDS-PAGE and subjected to immunoblotting using anti-HA antibodies to reveal Pdc2 or Sum2 proteins. Antibody against $\alpha$-tubulin was used as the control. The relative level of the protein of interest is indicated beneath each lane (average of two independent experiments). (C) Cytosolic native extracts from CHX-treated yeast strains as indicated were separated on $7 \%-47 \%$ sucrose gradients. The distribution of the rRNA is shown by absorption profiles at $260 \mathrm{~nm}$. As a positive control, $20 \mu \mathrm{g} / \mathrm{mL}$ puromycin was added to the culture medium $2 \mathrm{~h}$ before harvest (right panels). (D) The diverse roles of Pat1 proteins involved in translational control and mRNA decay in different species. 


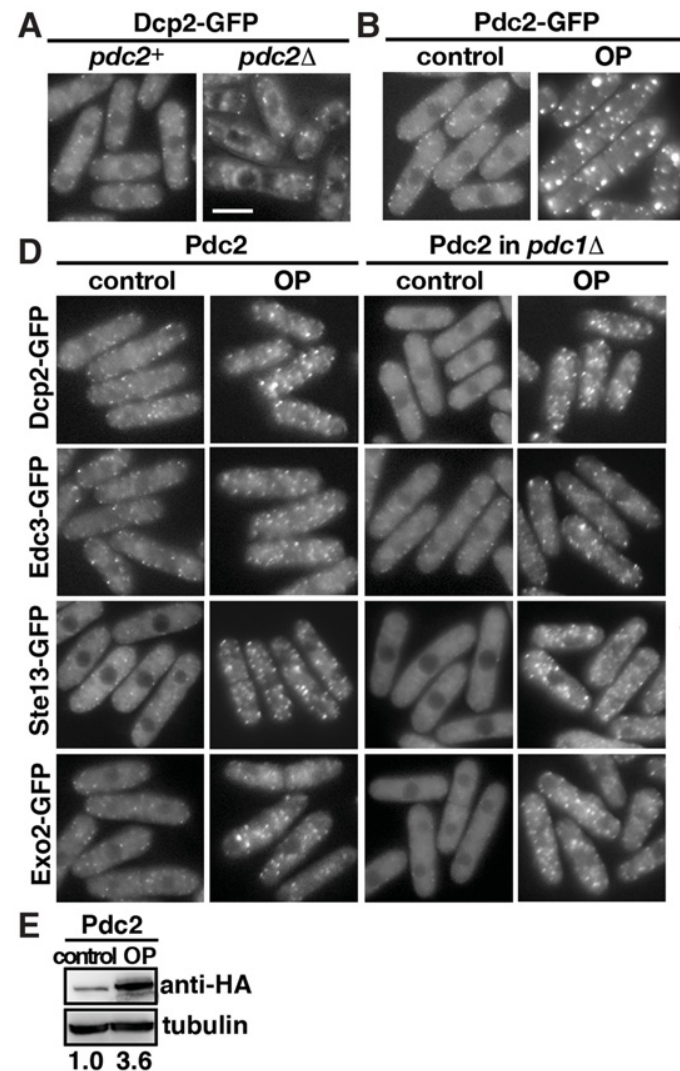

C

Pdc2(GFP)-OP Dcp2-tdT merged

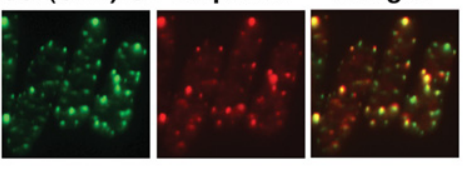

F
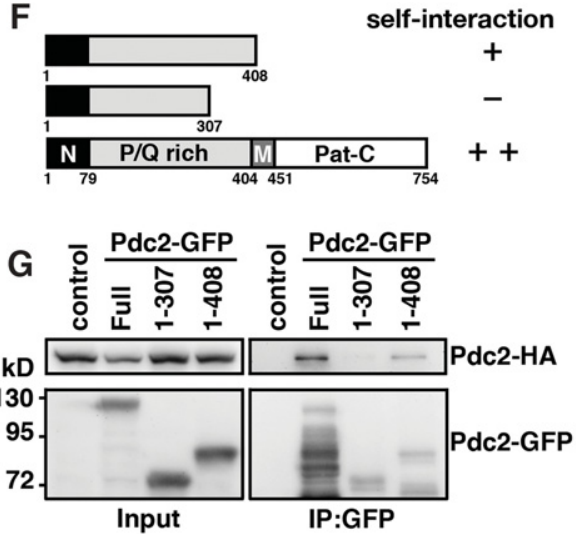

H

Pdc2 overexpressed in pdc1 $1 \Delta$

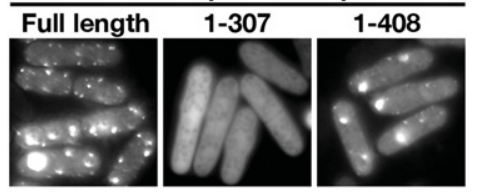

FIGURE 4. Pdc2 is important for P-body assembly. (A) Fluorescence micrographs of strains expressing Dcp2 GFP-fusion protein in wild-type cells or $p d c 2 \Delta$ mutants grown at $30^{\circ} \mathrm{C}$. Bar, $5 \mu \mathrm{m}$. (B) Fluorescence micrographs of strains expressing Pdc2 GFP-fusion protein from its own promoter (control) or overexpressed by the $n m t 1$ promoter (OP). (C) Merged images of fluorescence micrographs showing overexpressed GFP-Pdc2 (green) and Dcp2-tdTomato (red) localization in living cells grown at $30^{\circ} \mathrm{C}$. $(D)$ Fluorescence micrographs of strains with the indicated proteins tagged with GFP also expressing Pdc2 HA-fusion protein from its own promoter (control), or overexpressed by the nmt1 promoter (OP) in wild-type cells or pdc1 $\Delta$ mutants grown at $30^{\circ} \mathrm{C}$. (E) Representative Western blots of the extracts from strains used in $D$. (F) Schematic representation of the truncated Pdc2 proteins used in the following coimmunoprecipitation study. $(G)$ Coimmunoprecipitation was performed with extracts from the Pdc2 HA-tagging strain transformed with plasmid expressing full length or truncated Pdc2-GFP protein. GFP-trap affinity resin was used to pull down GFP fusion proteins. Immunoprecipitates were then analyzed by Western blotting using antibodies against GFP and HA. $(H)$ Fluorescence micrographs of strains expressing full length or C-terminal truncated Pdc2 GFP-fusion proteins in $p d c 1 \Delta$ mutants grown at $30^{\circ} \mathrm{C}$.

translation to demonstrate the dynamic range of the assay (right panel). Taking together, these results suggested that the roles of the P-body components Pat1 and Scd6 on translational repression were not conserved in S. pombe (Fig. 3D). Similar to human Patlb (Ozgur et al. 2010), Pdc2 does not have translational repression activity.

\section{Requirement of Pdc2 in fission yeast P-body assembly}

In Drosophila S2 cells, deletion of HPat affected P-body formation (Eulalio et al. 2007b). In contrast, in S. cerevisiae, the absence of Patl only had a slight effect on the size of P-bodies but did not lead to their loss (Teixeira and Parker 2007). To determine the requirement of Pdc2 in P-body assembly, we examined the ability of $p d c 2$ mutants to form P-bodies. As shown in Figure 4A, we observed that P-bodies could still form in $p d c 2$ mutants. In fact, P-body formation was enhanced with enlarged Dcp2 foci accumulation in these cells, probably due to the defect in RNA decapping (Fig. 2B), suggesting that Pdc2 was not absolutely required for the formation of P-bodies in S. pombe.

Next, we examined the effect of Pdc2 overexpression on P-body formation. Similarly to Pdc1 but not to the other components of P-bodies, Pdc2, when overexpressed, led to formation of multiple enlarged foci (Fig. 4B; CY Wang, unpubl.), which overlapped with the decapping enzyme Dcp2 to a certain degree (Fig. 4C). This suggested that Pdc2, like Pdc1, had a tendency to form aggregates and may contribute to the formation of P-bodies. In supporting this idea, though not as pronounced as Pdc1 (Wang et al. 2013), we found that overexpression of Pdc2 enhanced Pbody formation with multiple enlarged foci revealed by various components (Fig. 4D). This phenomenon occurred even in the absence of Pdc1, when P-body formation was compromised (right panel), suggesting that, in addition to Pdc1, Pdc2 also played a role in P-body formation. One important aspect of P-body assembly is the existence of a protein-protein interaction domain on numerous protein components 

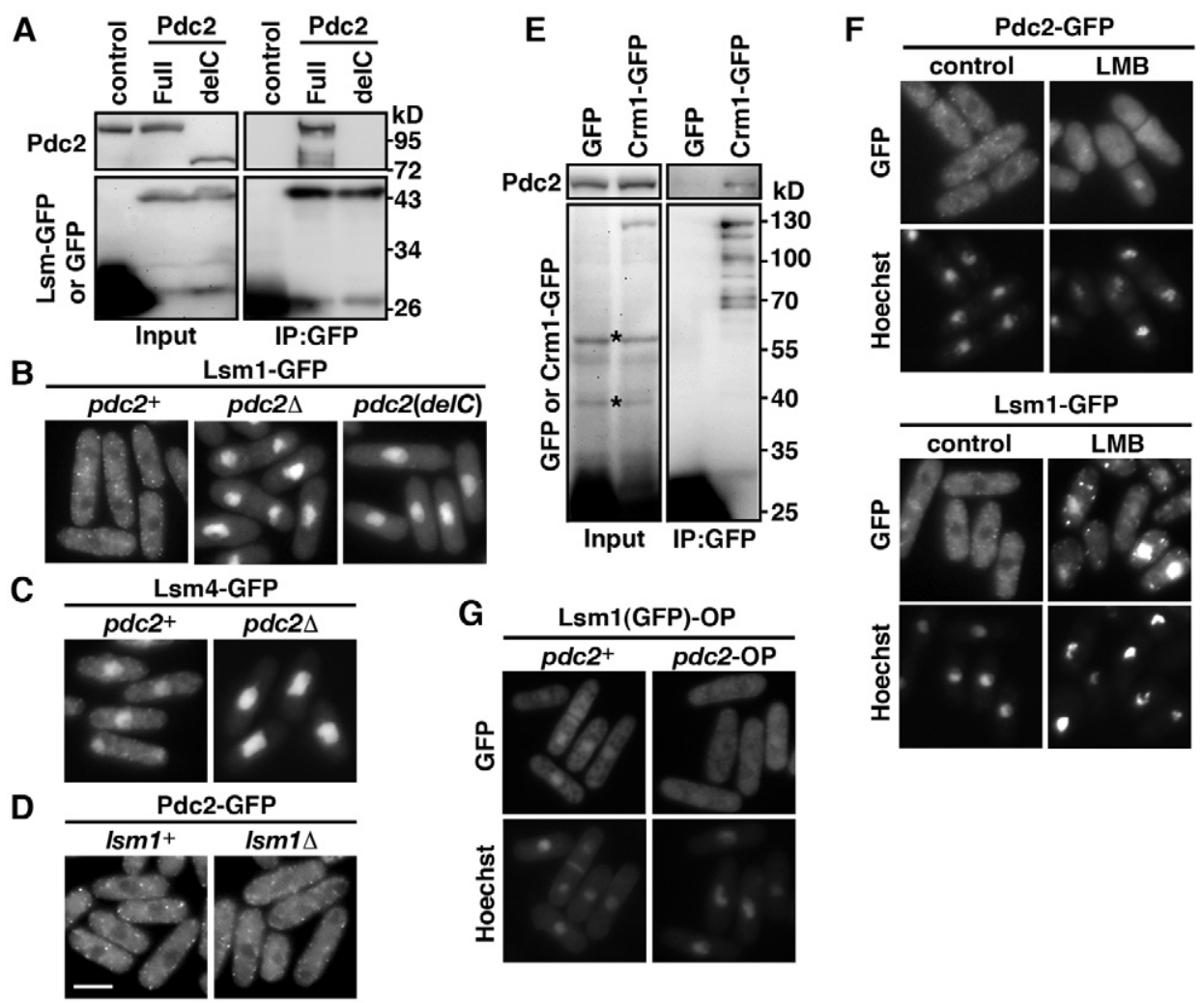

FIGURE 5. Pdc2 and Lsm1 are nucleo-cytoplasmic shuttling proteins. (A) Coimmunoprecipitation was performed with extracts prepared from Lsm1 GFP-tagging strains expressing full length or truncated Pdc2-Flag protein. GFP-trap affinity resin was used to pull down GFP fusion proteins. Immunoprecipitates were then analyzed by Western blotting using antibodies against GFP and Flag. $(B)$ Fluorescence micrographs of strains expressing Lsm1 GFP-fusion protein in $p d c 2$ deletion or C-terminal truncated (delC) mutants. $(C)$ Fluorescence micrographs of strains expressing Lsm4 GFP-fusion protein in $p d c 2$ mutant. $(D)$ Fluorescence micrographs of strains expressing Pdc2 GFP-fusion protein in $l s m 1$ mutant. Bar, $5 \mu \mathrm{m}$. (E) Coimmunoprecipitation was performed with extracts prepared from the Crm1 GFP-tagging strain expressing Pdc2-HA protein. GFP-trap affinity resin was used to pull down GFP fusion proteins. Immunoprecipitates were then analyzed by Western blotting using antibodies against GFP and HA. Asterisks indicate where the nonspecific bands cross-reacted with GFP antibody. $(F)$ Fluorescence micrographs of strains expressing Pdc2 or Lsm1 GFP-fusion protein in the presence of $100 \mathrm{ng} / \mathrm{mL}$ LMB for $3 \mathrm{~h}$ followed by Hoechst 33342 staining to reveal the nucleus. (G) Coexpression of Lsm1 from the $n m t 1$ promoter in strains expressing Pdc2 from its own promoter $\left(p d c 2^{+}\right)$or overexpressed by the $n m t 1$ promoter (pdc2-OP) with Hoechst nuclear staining.

(Jonas and Izaurralde 2013). In addition, proteins required for the assembly of P-bodies often contain self-interacting domains such as the coiled-coil domain of Pdc1 (Wang et al. 2013). By analogy, Pdc2 contains a $\mathrm{P} / \mathrm{Q}$ rich region, an aggregation-prone domain (Fig. 4F). We thus examined the ability of Pdc2 for self-interaction. Plasmids encoding Pdc2-GFP proteins harboring a series of deletions in the C terminus were coexpressed with Pdc2-HA in yeast cells. We found that Pdc2-GFP specifically pulled down Pdc2-HA, and the segment residues 307 to 408 of Pdc2 were necessary for the interaction (Fig. 4G). In line with these results, the accumulation of the overexpressed Pdc2 in cytoplasmic foci was affected by the lack of binding to other P-body proteins (Fig. $4 \mathrm{H}$, right panel), and the deletion of the self-interaction region further reduced its accumulation (Fig. $4 \mathrm{H}$, middle panel). Together, these results suggested that although not absolutely essential for P-body assembly, Pdc2 had an overlapping function with Pdc1 to enhance P-body formation.

\section{Pdc2 and Lsm1 are nucleo-cytoplasmic shuttling proteins}

In addition to the interaction with the components of P-bodies described above, Pat1 interacts with the Lsm1-7 complex and plays an important role in mRNA decay (Marnef and Standart 2010). We asked whether Pdc2 would similarly interact with Lsm1. As shown in Figure 5A, we found that Lsm1-GFP specifically pulled down Pdc2, and the C-terminal region of Pdc2 (residues 499-754) responsible for the interaction was identified. Next, we examined how Pdc2 affected the cellular localization of Lsm1 proteins and found that, in the absence of a Pdc2 or Pdc2 mutant that failed to interact with Lsm1, Lsm1 accumulated in the nucleus (Fig. 5B). Similarly, Lsm 4 enriched in the nucleus when $p d c 2^{+}$was deleted (Fig. 5C). In contrast, deletion of $l s m 1^{+}$did not affect the localization of Pdc2 (Fig. 5D). This was in sharp contrast to the situation in S. cerevisiae, where Pat1 was relocalized to the nucleus upon deletion of LSM1 (Teixeira and Parker 


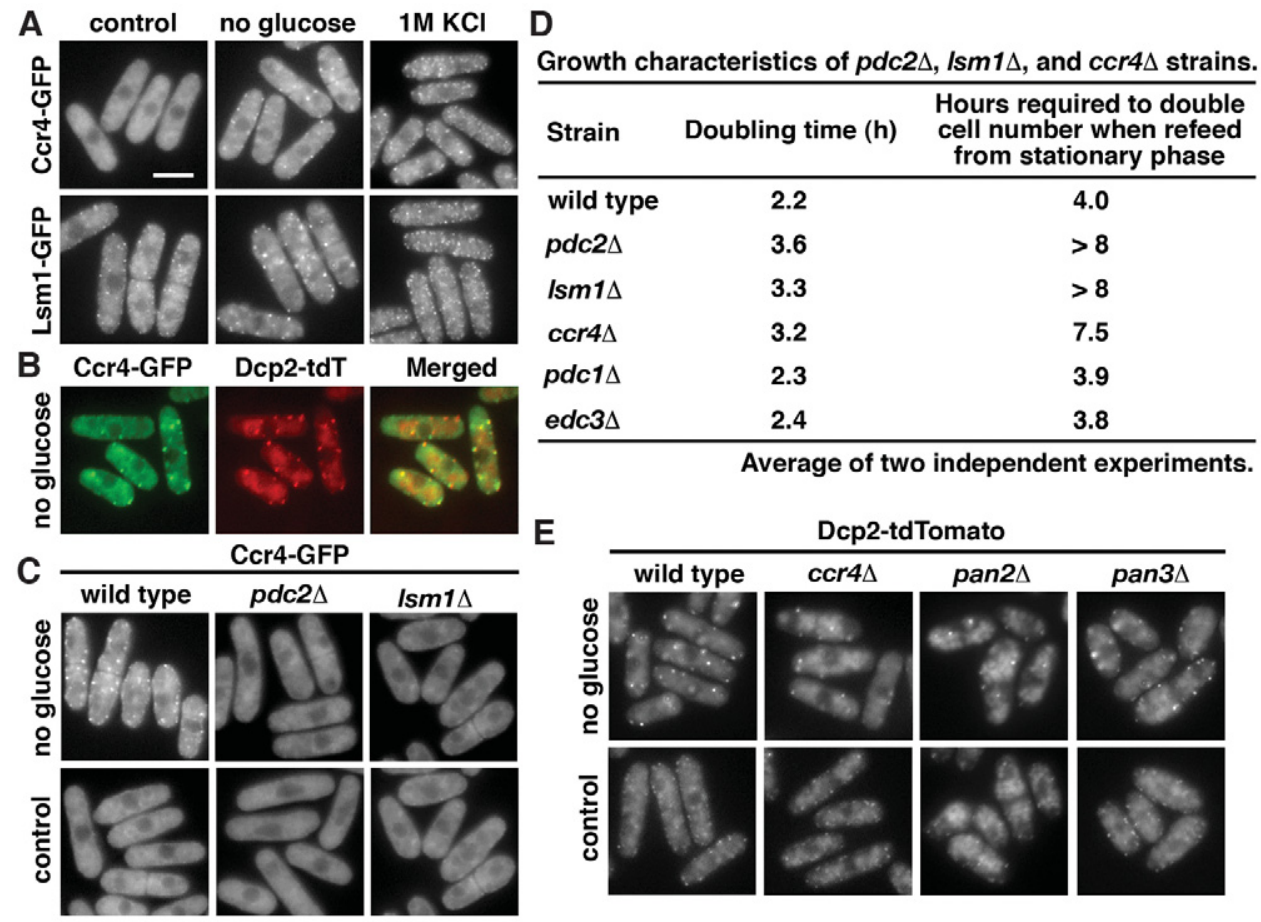

FIGURE 6. Recruitment of the deadenylase Ccr4 to P-bodies in the absence of glucose depends on the Pdc2-Lsm1 complex. $(A)$ Fluorescence micrographs of strains expressing Ccr4 or Lsml GFP-fusion proteins grown at $30^{\circ} \mathrm{C}$ (control), or after deprivation of glucose or exposure to $1 \mathrm{M} \mathrm{KCl}$ for $15 \mathrm{~min}$. Bar, $5 \mu \mathrm{m}$. (B) Merged images of fluorescence micrographs showing Ccr4-GFP (green) and Dcp2-tdTomato (red) localization in living cells after deprivation of glucose for $15 \mathrm{~min}$. (C) Fluorescence micrographs of strains expressing Ccr4 GFP-fusion protein in $p d c 2$ or $l s m 1$ mutants grown at $30^{\circ} \mathrm{C}$ (control), or after deprivation of glucose for $15 \mathrm{~min}$. (D) Growth characteristics of the strains indicated at $30^{\circ} \mathrm{C}$ (Doubling time) or after refeed from stationary phase to re-enter the cell cycle. $(E)$ Fluorescence micrographs of strains expressing Dcp2 GFP-fusion protein in cells defective in deadenylase Ccr4 or Pan2-Pan3 grown at $30^{\circ} \mathrm{C}$ (control), or after deprivation of glucose for $15 \mathrm{~min}$.

2007), suggesting that despite sharing a similar protein composition, the underlying molecular mechanism can be distinct between species. These results indicated that, as demonstrated for human Pat1b protein (Marnef et al. 2012), Pdc2 was likely a nuclear-cytoplasmic shuttling protein playing a role in translocating Lsm1 from nucleus to cytoplasm. In supporting this notion and in agreement with a previously described systematic localisome study (Matsuyama et al. 2006), we found that Pdc2 interacted with the Crm1, a nuclear exportin involved in protein export (Fig. 5E), and both Pdc2 and Lsm 1 accumulated in the nucleus when nuclear export was inhibited by leptomycin B (LMB) (Fig. 5F). In supporting the role of $\mathrm{Pdc} 2$ in decreasing the concentration of Lsm 1 in the nucleus, we found that Lsm 1 normally presented in the cytoplasm, and when overexpressed, became accumulated in the nucleus (Fig. 5G, left panel) as previously reported by Matsuyama et al. (2006). Coexpression of Pdc2 in these cells significantly reduced the amount of Lsm1 in the nucleus (right panel).

\section{Recruitment of the deadenylase Ccr4 to P-bodies depends on Pdc2-Lsm1}

To further pursue the role of Pat1 proteins in coupling deadenylation and decapping, we examined the cellular localiza- tion of the deadenylase Ccr4 proteins in $p d c 2$ mutants. Interestingly, we found that unlike Lsm1 and other components of P-bodies, which accumulated in cytoplasmic foci that can be readily detected in unstressed cells (Wang et al. 2013), Ccr4 did not accumulate in growing cells under favorable conditions and was only recruited to these foci upon stress (Fig. 6A), overlapping with the decapping enzyme Dcp2 (Fig. 6B). As shown in Figure 6C, the recruitment of Ccr4 to P-bodies in the absence of glucose largely depended on Lsm1. Similar results were observed in the pdc2 mutant, suggesting that the Pdc2-Lsm1 complex was important for recruitment of Ccr4 to P-bodies. The distinct cellular localization of Ccr4 as compared to other components of P-bodies led us to speculate that these proteins might play a role in cellular response to environmental stimuli. In keeping with this idea, mutants depleted for Ccr4 or Pdc2-Lsm1 complex showed a slow-growth phenotype and were defective in recovery from glucose starvation with a much longer time to re-enter the cell cycle (Fig. 6D). Together, these results were consistent with a function of Pdc2 in coupling deadenylation and decapping that might have implications in the cellular response to environmental stress.

We also investigated how deadenylases Ccr4 and Pan2-Pan3 affected the formation of P-bodies. As shown in Figure 6E, the ccr4 mutant did not show a significant difference in 


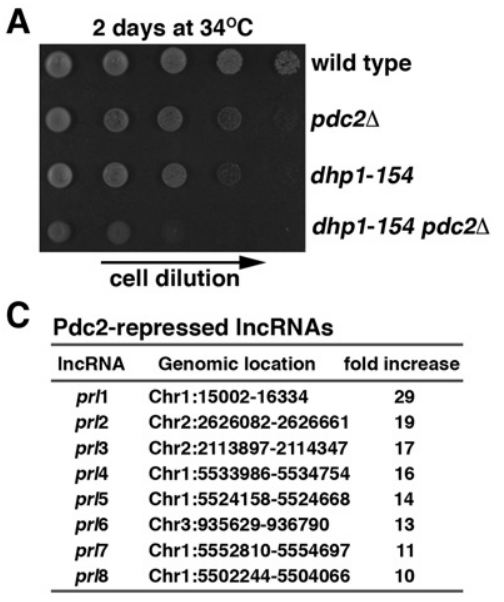

B

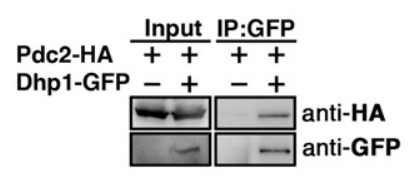

D
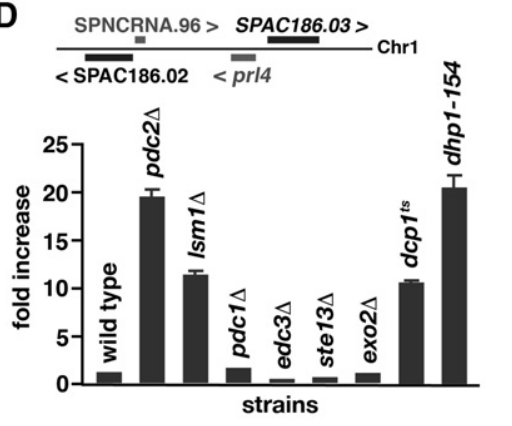

FIGURE 7. Pdc2 interacts with Dhp1 to regulate lncRNA. (A) Tenfold serial dilution of the indicated strains spanning from the range of $10^{2}-10^{6}$ cells were spotted onto a YE-agar plate and photographed after $2 \mathrm{~d}$ incubation at $34^{\circ} \mathrm{C}(B)$ Coimmunoprecipitation was performed with extracts prepared from Dhp1 GFP-tagging strains expressing Pdc2-HA proteins. GFP-trap affinity resin was used to pull down GFP fusion proteins. Immunopreciptates were then analyzed by Western blotting using antibodies against GFP and HA. (C) Characteristic features of Pdc2-repressed lncRNAs identified by high-throughput RNA sequencing. (D) Schematic representation of the genomic localization of prl4 lncRNA on chromosome I. Total RNA from cultures of the indicated strains grown at $30^{\circ} \mathrm{C}$, or in the case of $d c p 1$ and $h d p 1$, temperature-sensitive mutants at the restricted temperature of $36^{\circ} \mathrm{C}$ for $3 \mathrm{~h}$ were reverse transcribed using oligo(dT) primers. The cDNAs were amplified using quantitative PCR and SYBR green in triplicate with primers specific for prl4. RNA amounts normalized to $c d c 2$ mRNA were expressed relative to the wild type.

the concentration of Dcp2 in P-bodies. It has been shown that in mammalian cells, Pan3 knockdown resulted in Pbody reduction (Zheng et al. 2008). However, as shown in Figure 6E, in S. pombe pan2 and pan3 mutants, Dcp2 accumulated in P-bodies in a manner similar to that of wildtype cells. We concluded that of the fission yeast deadenylases, neither Ccr4 nor Pan2-Pan3 had a large impact on P-body assembly.

\section{Pdc2 physically and genetically interacts with nuclear 5'-3' exonuclease Dhp1}

The nuclear localization of Pdc2 suggests that it may also function in the nucleus. In our study of Dcp2-interacting proteins, the nuclear $5^{\prime}-3^{\prime}$ exoribonuclease Dhp1, the ortholog of budding yeast Ratl protein was identified (S. pombe GeneDB Protein-Protein Interaction Predictor, Bähler Laboratory) and confirmed by coimmunoprecipitation (CY Wang, unpubl.). In view of the close interaction between Dcp2 and Pdc2, we set out to determine whether Pdc2 interacted with Dhp1 genetically or physically. As shown in Figure $7 \mathrm{~B}$, although predominantly in the cytoplasm, Pdc2 specifically interacted with Dhp1 as demonstrated by coimmunoprecipitation. In line with this idea, a synthetic lethality was observed between $p d c 2$ and dhp1-154 temperature-sensitive mutants (Fig. 7A), suggesting that Pdc2 might have a nuclear role in some aspect of Dhpl function.

\section{Pdc2 regulates IncRNAs}

Recently, a role of Rat1, the ortholog of Dhp1 in S. cerevisiae, together with the Dcp2 decapping enzyme in regulating IncRNAs has been described (Geisler et al. 2012). Given the close interaction between Pdc2 and Dhp1, we explored the possibility that Pdc2 might have a role in regulating lncRNAs by highthroughput RNA sequencing. Consistent with our prediction that Pdc2 might regulate $\operatorname{lncRNA}$, in addition to a significant elevation in the level of several previously characterized lncRNAs, our analysis identified several previously unannotated lncRNAs based on their accumulation in $p d c 2$ mutants (over 10-fold increase as the cutoff point due to the relatively low abundance of lncRNAs in the genome). We referred to these IncRNAs as Pdc2-repressed lncRNAs ( $p r l 1-8$ ) (Fig. 7C). The presence of prl4 in the $p d c 2$ mutant was verified by real-time PCR (Fig. 7D) (a complete analysis and characterization of these lncRNAs will form the basis of a future report). An elevation at the level of the prl4 transcript was also observed in the $l s m 1$ mutant as well as in $d c p 1$ and $d h p 1$ temperature-sensitive mutants grown at restricted temperature. Together, these data were consistent with a function of Pdc2-Lsm1 together with Dhp1 and the decapping enzyme Dcp1-Dcp2, but not with other components of P-bodies in regulating lncRNAs.

\section{DISCUSSION}

Pat1 was first identified as a protein associated with topoisomerase II (Wang et al. 1996). Since then, no other studies have focused on this nuclear function. Rather, Pat 1 has been reported to play important roles in translational control and mRNA decay (Marnef and Standart 2010). This study begins to reveal the roles of Pdc2/Pat1 proteins in S. pombe. It is of interest to note that despite sharing similar protein composition, species specificity has evolved. Our data showed that S. pombe Pdc2 and S. cerevisiae Pat1 differed significantly in terms of their functions (Fig. 3D) and interaction with Lsm1 (Fig. 5), highlighting the importance of cross-species study. While in S. cerevisiae, Patl is a regulator of both mRNA decay and translational repression; the role of human Pat $1 \mathrm{~b}$ and Pdc2 in S. pombe appears to be restricted to mRNA degradation. Together with our previous study of the identification of Edc4-like proteins in S. pombe (Wang et al. 2013), these results led us to suggest that the whole complex including the decapping enzyme and its coactivators have coevolved 
together. In supporting this idea, phylogenetic analysis revealed that $S$. pombe Pdc2 was clustered within a monophyletic branch with the Pat1 sequence from other eukaryotes including A. thaliana, D. melanogaster, and Homo sapiens, while S. cerevisiae Pat1 was more distantly related to the other species (Supplemental Fig. 1). Similar results were obtained for Lsm1, indicating that these proteins might have evolved together and the way they interacted changed as well. In addition, our data also revealed a function of P-body in cellular response to environmental stress (Fig. 8A) and a potential novel nuclear function of Pdc2 in concert with Dhp1 (Fig. 8B).

\section{Pdc2 in P-body function}

In keeping with the role in mRNA decay, Pdc2 interacted with the decapping enzyme Dcp2 and its coactivators, including Edc3, Pdc1, and Ste13, as well as the $5^{\prime}-3^{\prime}$ exoribonuclease Exo2, and localized to the P-bodies (Fig. 1). P-body residency was also observed in S. cerevisiae, Caenorhabditis elegans, Drosophila, and human cells (Teixeira and Parker 2007; Boag et al. 2008). However, it is not in complete agreement whether Pat1 proteins are essential for P-body assembly, possibly arising from experimental and/or cell variation. Our data showed that Pdc2 had the potential to be self-associated, a property that might facilitate P-body assembly (Fig. 4). When overexpressed, Pdc2 affected the formation of P-bodies even in the absence of Pdcl, suggesting that although not absolutely essential for P-body assembly, Pdc2 might play a role in P-body formation.

In addition to the interaction described above, Pdc2 interacted with Lsm1 and perhaps the whole Lsm1-7 complex (Fig. 5). Consistent with the proposed role of Patl proteins in coupling deadenylation and decapping, although Pdc2

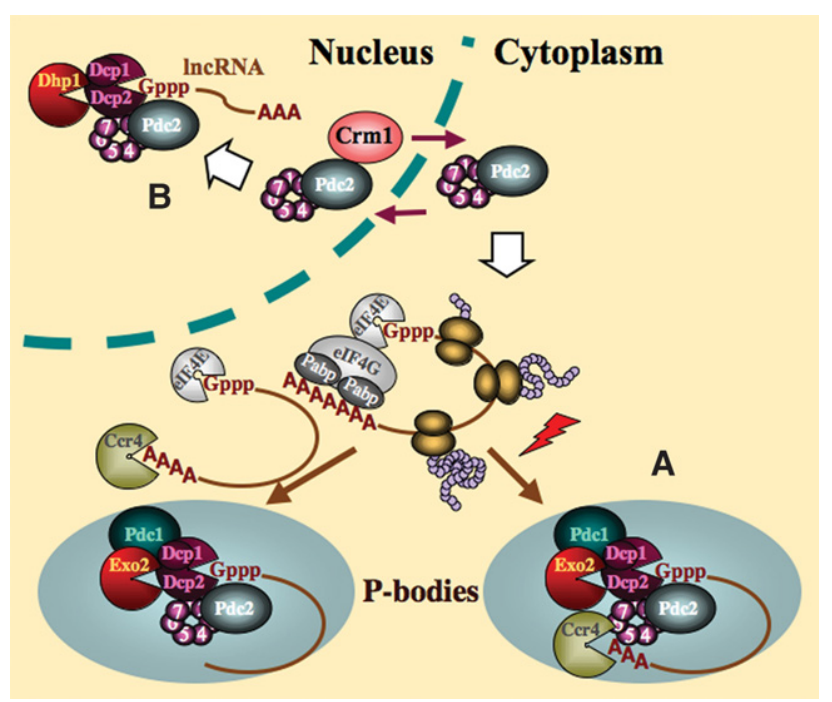

FIGURE 8. A model summarizing the roles of Pdc2 in P-body function and regulating lncRNA in the nucleus. did not affect deadenylation, we found that the Pdc2-Lsm1 complex was important for the recruitment of Ccr4 to Pbodies (Fig. 6). Unlike other components of P-bodies, Ccr4 did not accumulate in fission yeast P-bodies in cells growing under favorable conditions and was only recruited to these foci upon stress in a manner that depended on the Pdc2Lsm1 complex. Similarly, in S. cerevisiae, during midlog growth, only limited amounts of Ccr4 were seen in P-bodies when compared with other factors (Teixeira and Parker 2007), and it was clearly observed to accumulate in P-bodies after deprivation of glucose. This is in contrast to the observations that Pat $1 \mathrm{~b}$ is tightly associated with the Ccr4-Caf1Not1 deadenylation complex in human cells (Ozgur et al. 2010) and Ccr4 is concentrated in discrete foci that can be readily detected in mammalian cells (Cougot et al. 2004). The requirement of deadenylation in the assembly of P-bodies in different species diverged also. While, in yeast, deadenylases only have a minor role in the assembly of P-bodies (Teixeira and Parker 2007), deadenylation is a prerequisite for P-body formation in mammalian cells (Zheng et al. 2008).

\section{Pdc2 in cellular response to environmental stress}

Our results also indicated that Pdc2 together with Ccr4 has a role in cellular response to environmental stress (Fig. 6). In keeping with this idea, cells defective in the Ccr4 deadenylase or Pdc2-Lsm1 complex are hypersensitive to the composition of the surrounding medium with a defect in recovery from glucose starvation that is not shared by other components of P-bodies. The recruitment of the deadenylase Ccr4 to P-bodies upon stress may facilitate the degradation of mRNAs. However, Pdc2 does not have a large impact on the overall profile of transcripts, which are down-regulated after deprivation of glucose (data not shown), although it remains possible that Pdc2 affects specific transcripts. Alternatively, P-bodies may serve as mRNA storage depots, particularly during cellular stress, as suggested by a recent study in human cells (Aizer et al. 2014). Experiments are under way to explore this possibility.

\section{Pdc2 nuclear function}

In keeping with the notion that Pat 1 was a nucleocytoplasmic protein functioning also in the nucleus, a function of Pdc2Lsm1, in concert with Dhp1, regulating lncRNAs by promoting its decapping/destruction in the nucleus was suggested based on the following observations. In addition to the physical interaction between Dcp2 and Dhp1, we found that Pdc2 physically and genetically interacted with Dhp1 (Fig. 7). In line with a role in regulating lncRNA, several previously unannotated lncRNAs accumulated in pdc2 mutants (Fig. 7C). Among them, an elevation in the level of the prl4 transcript was also observed in the $l s m 1$ mutant as well as in the $d c p 1$ and dhpl temperature-sensitive mutants (Fig. 7D). The 
accumulation of the prl4 transcripts suggested that they are normally targeted for degradation. In support of this idea, a recent report has presented evidence that nuclear $5^{\prime}-3^{\prime}$ exonucleolytic digestion by Rat1, the budding yeast ortholog of Dhp1, contributes to lncRNA decay (Geisler et al. 2012). Although it was suggested that this process was independent of the decapping activators Lsm1 and Dhh1, given the diverse functions of Lsm1 in different organisms, our observation was not unanticipated. It will be of interest to test whether the process depends on Pat 1 in S. cerevisiae, and whether human Patb1 also regulates lncRNA. At present, the biological functions of the lncRNAs identified in this study remain unclear, as most of them are located between previously uncharacterized genes that require further attention. Regardless of the possible answers to these questions, the study herein adds significantly to the versatility and complexity of the pathway and the mechanism in which the decapping enzyme and its coactivators participated.

\section{MATERIALS AND METHODS}

\section{Fission yeast strains and methods}

Conditions for growth, maintenance, and genetic manipulation of fission yeast were as described previously (Wen et al. 2010). A complete list of the strains used in this study is given in Supplemental Table 1. One-step gene disruption or modification via homologous recombination was performed following PCR-mediated generation of $\mathrm{ura4}^{+}$or KanMX selectable cassettes flanked by 80-bp segments from appropriate regions of the genes of interest using oligonucleotides described in Supplemental Table 2. Except where otherwise stated, strains were grown at $30^{\circ} \mathrm{C}$ in yeast extract (YE) or Edinburgh Minimal Medium (EMM2) with appropriate supplements. Where necessary, gene expression from the $n m t 1$ promoter was repressed by the addition of $5 \mu \mathrm{M}$ thiamine to the culture medium.

\section{Plasmids}

Plasmid for expression or truncation of Pdc2 was constructed by PCR amplification of the corresponding open reading frame from $S$. pombe cDNA, using the primer pairs described in Supplemental Table 2, and subsequently ligated as SalI and NotI fragments into plasmids derived from pREP41 encoding a GFP tag at its C terminus following the NotI site.

\section{Microscopy}

Visualization of tdTomato and green fluorescent protein (GFP)tagged proteins in living cells was performed at room temperature. In some experiments, living cells growing in EMM medium were stained by the addition of $5 \mu \mathrm{g} / \mathrm{mL}$ bis-benzimide (Hoechst 33342, Sigma) before examination by fluorescence microscopy. Images acquired from a Leica DM RA2 microscope equipped with a Leica DC 350F camera were assembled using Adobe PhotoShop.

\section{Antibodies and immunoprecipitation}

Yeast extracts prepared by alkaline extraction as described previously (Wen et al. 2010) were resolved on SDS-PAGE before subjected to Western blotting using anti-GFP antibody (Abcam) to reveal GFPfusion proteins. Antibody against HA was from Roche. Anti-Flag M2 antibody was from Sigma-Aldrich. Antibody against a-tubulin (Sigma-Aldrich) was used as control. Anti-ubiquitin antibody was from Millipore.

For immunoprecipitation, $2 \times 10^{8}$ cells were lysed in $200 \mu \mathrm{L}$ NP-40 buffer $\left(6 \mathrm{mM} \mathrm{Na}_{2} \mathrm{HPO}_{4}, 4 \mathrm{mM} \mathrm{NaH}_{2} \mathrm{PO}_{4}, 1 \% \mathrm{NP}-40,150 \mathrm{mM} \mathrm{NaCl}\right.$, $2 \mathrm{mM}$ EDTA, $50 \mathrm{mM} \mathrm{NaF}, 0.1 \mathrm{mM} \mathrm{Na}_{3} \mathrm{VO}_{4}, 1 \mathrm{mM}$ PMSF, $1 \mathrm{mM}$ DTT, Complete protease inhibitor cocktail) by vortexing with acidwashed glass beads. The lysate was clarified by centrifugation and GFP-fusion proteins were retrieved using GFP-Trap coupled agarose beads (Chromotek), following the manufacturer's instructions.

\section{RNA isolation and splinted ligation RT-PCR}

Total RNA was isolated by hot phenol extraction and purified using RNeasy (QIAGEN). Splinted ligation of RNA was performed as described previously (Wang et al. 2013). Briefly, an RNA anchor was ligated to the free hydroxyl of a decapped rps 23 mRNA facilitated by a gene-specific DNA splint. After removal of the splint by the DNase I (Roche), rps23 gene-specific RT primers were used for reverse transcription to synthesize cDNA using SuperScript III (Invitrogen) and then PCR amplified using a primer complementary to the RNA anchor and an rps23 specific reverse primer. For tobacco acid pyrophosphatase (TAP) treatment, $10 \mu \mathrm{g}$ total RNA was decapped by treatment with $20 \mathrm{U}$ of RNase Inhibitor Plus (Promega) and $5 \mathrm{U}$ tobacco acid pyrophosphatase (Epicentre Biosystems) in the supplied $1 \times$ TAP buffer for $30 \mathrm{~min}$ at $37^{\circ} \mathrm{C}$ before splinted ligation of RNA.

\section{PCR poly(A) test}

Polyadenylation tests were performed as described previously (Win et al. 2006) using the $3^{\prime}$ rapid amplification of cDNA ends system (Invitrogen) and then PCR amplified using primer specific for rps23 mRNA and the adapter primer. PCR products were cloned (TOPO TA Cloning, Invitrogen) and sequenced using an ABI sequencer and ABI PRISM dRhodamine reagents (Applera UK).

\section{Polysome profile analysis}

Polysomes were obtained as previously described (Wang et al. 2012). Cycloheximide $(100 \mu \mathrm{g} / \mathrm{mL})$ was added to $50 \mathrm{~mL}$ of cultures at an $\mathrm{OD}_{600}$ of 0.5 grown at $30^{\circ} \mathrm{C}$. The cultures were harvested and processed for polysome profiling on $7 \%-47 \%$ sucrose gradients. Profiles were obtained by online measurements of $A_{260 \mathrm{~nm}}$. As a positive control, $20 \mu \mathrm{g} / \mathrm{mL}$ puromycin was added to the culture medium to repress translation $2 \mathrm{~h}$ before harvest.

\section{RNA extraction and library construction}

Total RNA was isolated using illustra RNAspin Mini RNA Isolation Kit (GE Healthcare). Quality of RNA samples was analyzed by Agilent BioAnalyzer 2100 and a Qubit fluorometer. All RNA samples 
used were of high quality (RIN > 9) and with a concentration between $50 \mathrm{ng} / \mu \mathrm{L}$ and $500 \mathrm{ng} / \mu \mathrm{L}$. A library was prepared using TruSeq Stranded Total RNA Library Prep Kit (Illumina) after depletion of ribosomal RNA using the Ribo-Zero rRNA removal kit (Illumina).

\section{Sequencing data analysis}

All libraries prepared in a strand specific manner were sequenced on Illumina HiSeq 2000 generating 25 million paired-end reads of length of 90 bases per end in each sample for $p d c 2$ mutant and wild-type cells (Gene Direx). Adapter sequences were removed and reads were mapped to NONCODE V3.0 (http://www.noncode .org/) by Cuffcompare. Ribosomal RNA data were removed by Tophat (https://ccb.jhu.edu/software/tophat/index.shtml). Novel ncRNA prediction is performed by CPC (http://cpc.cbi.pku.edu. $\mathrm{cn} /$ ). Sequencing reads were aligned to the fission yeast genome (PomBase). Differential expression is analyzed by Cufflinks (http ://cole-trapnell-lab.github.io/cufflinks/). All parameters were applied by default setting.

\section{Quantitative polymerase chain reaction (QPCR)}

Quantitative PCR was performed using SYBR GREEN PCR Master Mix (Applera UK) with gene-specific primers. A complete list of primers used in this study is given in Supplemental Table 2. Samples were run in triplicate on the Applied Biosystems 7300 Real-Time PCR System (Applera UK). Relative quantities of the transcript were determined using the $2^{-\Delta \Delta c t}$ formula, where $C t$ is defined as the cycle at which fluorescence is determined to be statistically above background, $\Delta C t$ is the difference in $\mathrm{Ct}$ of the gene of interest and $C t$ of the $c d c 2$ normalizer gene, and $\Delta \Delta C t$ is the difference in $\Delta C t$ of the strain tested and $\Delta C t$ of the control cells.

\section{SUPPLEMENTAL MATERIAL}

Supplemental material is available for this article.

\section{ACKNOWLEDGMENTS}

This work was supported by the National Health Research Institute (MG-104-PP-09) and the Ministry of Science and Technology (1022311-400-004-MY3), Taiwan. We thank Chris J. Norbury, Gerald Smith, and the Yeast Genetic Resource Center Japan for yeast strains, and Ching-Ting Huang and Wei-Ling Wen for technical support.

Received October 27, 2016; accepted December 21, 2016.

\section{REFERENCES}

Aizer A, Kalo A, Kafri P, Shraga A, Ben-Yishay R, Jacob A, Kinor N, Shav-Tal Y. 2014. Quantifying mRNA targeting to P-bodies in living human cells reveals their dual role in mRNA decay and storage. J Cell Sci 127: 4443-4456.

Boag PR, Atalay A, Robida S, Reinke V, Blackwell TK. 2008. Protection of specific maternal messenger RNAs by the P body protein CGH-1 (Dhh1/RCK) during Caenorhabditis elegans oogenesis. J Cell Biol 182: 543-557.

Braun JE, Tritschler F, Haas G, Igreja C, Truffault V, Weichenrieder O, Izaurralde E. 2010. The $\mathrm{C}$-terminal $\alpha$ - $\alpha$ superhelix of Pat is required for mRNA decapping in metazoa. EMBO J 29: 2368-2380.
Chang CT, Bercovich N, Loh B, Jonas S, Izaurralde E. 2014. The activation of the decapping enzyme DCP2 by DCP1 occurs on the EDC4 scaffold and involves a conserved loop in DCP1. Nucleic Acids Res 42: 5217-5233.

Cougot N, Babajko S, Seraphin B. 2004. Cytoplasmic foci are sites of mRNA decay in human cells. J Cell Biol 165: 31-40.

Erickson SL, Corpuz EO, Maloy JP, Fillman C, Webb K, Bennett EJ, Lykke-Andersen J. 2015. Competition between decapping complex formation and ubiquitin-mediated proteasomal degradation controls human Dcp2 decapping activity. Mol Cell Biol 35: 2144-2153.

Eulalio A, Behm-Ansmant I, Izaurralde E. 2007a. P bodies: at the crossroads of post-transcriptional pathways. Nat Rev Mol Cell Biol 8: 9-22.

Eulalio A, Behm-Ansmant I, Schweizer D, Izaurralde E. 2007b. P-body formation is a consequence, not the cause, of RNA-mediated gene silencing. Mol Cell Biol 27: 3970-3981.

Fenger-Gron M, Fillman C, Norrild B, Lykke-Andersen J. 2005. Multiple processing body factors and the ARE binding protein TTP activate mRNA decapping. Mol Cell 20: 905-915.

Geisler S, Lojek L, Khalil AM, Baker KE, Coller J. 2012. Decapping of long noncoding RNAs regulates inducible genes. Mol Cell 45: 279-291.

Haas G, Braun JE, Igreja C, Tritschler F, Nishihara T, Izaurralde E. 2010. HPat provides a link between deadenylation and decapping in metazoa. J Cell Biol 189: 289-302.

Hatfield L, Beelman CA, Stevens A, Parker R. 1996. Mutations in transacting factors affecting mRNA decapping in Saccharomyces cerevisiae. Mol Cell Biol 16: 5830-5838.

Jonas S, Izaurralde E. 2013. The role of disordered protein regions in the assembly of decapping complexes and RNP granules. Genes Dev 27: 2628-2641.

Marnef A, Standart N. 2010. Patl proteins: a life in translation, translation repression and mRNA decay. Biochem Soc Trans 38: 1602-1607.

Marnef A, Weil D, Standart N. 2012. RNA-related nuclear functions of human Pat1b, the P-body mRNA decay factor. Mol Biol Cell 23: 213-224.

Matsuyama A, Arai R, Yashiroda Y, Shirai A, Kamata A, Sekido S, Kobayashi Y, Hashimoto A, Hamamoto M, Hiraoka Y, et al. 2006. ORFeome cloning and global analysis of protein localization in the fission yeast Schizosaccharomyces pombe. Nat Biotechnol 24: 841-847.

Nissan T, Rajyaguru P, She M, Song H, Parker R. 2010. Decapping activators in Saccharomyces cerevisiae act by multiple mechanisms. Mol Cell 39: 773-783.

Ozgur S, Chekulaeva M, Stoecklin G. 2010. Human Pat1b connects deadenylation with mRNA decapping and controls the assembly of processing bodies. Mol Cell Biol 30: 4308-4323.

She M, Decker CJ, Chen N, Tumati S, Parker R, Song H. 2006. Crystal structure and functional analysis of Dcp2p from Schizosaccharomyces pombe. Nat Struct Mol Biol 13: 63-70.

Teixeira D, Parker R. 2007. Analysis of P-body assembly in Saccharomyces cerevisiae. Mol Biol Cell 18: 2274-2287.

Wang X, Watt PM, Louis EJ, Borts RH, Hickson ID. 1996. Pat1: a topoisomerase II-associated protein required for faithful chromosome transmission in Saccharomyces cerevisiae. Nucleic Acids Res 24: 4791-4797.

Wang CY, Wen WL, Nilsson D, Sunnerhagen P, Chang TH, Wang SW. 2012. Analysis of stress granule assembly in Schizosaccharomyces pombe. RNA 18: 694-703.

Wang CY, Chen WL, Wang SW. 2013. Pdc1 functions in the assembly of P bodies in Schizosaccharomyces pombe. Mol Cell Biol 33: 1244-1253.

Wen WL, Stevenson AL, Wang CY, Chen HJ, Kearsey SE, Norbury CJ, Watt S, Bahler J, Wang SW. 2010. Vgl1, a multi-KH domain protein, is a novel component of the fission yeast stress granules required for cell survival under thermal stress. Nucleic Acids Res 38: 6555-6566.

Win TZ, Draper S, Read RL, Pearce J, Norbury CJ, Wang SW. 2006. Requirement of fission yeast Cid14 in polyadenylation of rRNAs. Mol Cell Biol 26: 1710-1721.

Zheng D, Ezzeddine N, Chen CY, Zhu W, He X, Shyu AB. 2008. Deadenylation is prerequisite for P-body formation and mRNA decay in mammalian cells. J Cell Biol 182: 89-101. 

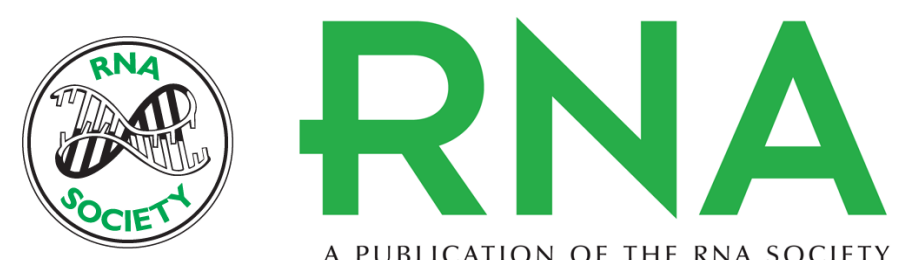

A PUBLICATION OF THE RNA SOCIETY

\title{
Involvement of fission yeast Pdc2 in RNA degradation and P-body function
}

\author{
Chun-Yu Wang, Yi-Ting Wang, Wan-Yi Hsiao, et al.
}

RNA 2017 23: 493-503 originally published online December 28, 2016

Access the most recent version at doi:10.1261/rna.059766.116

\section{Supplemental http://rnajournal.cshlp.org/content/suppl/2016/12/28/rna.059766.116.DC1 \\ Material}

References This article cites 26 articles, 17 of which can be accessed free at: http://rnajournal.cshlp.org/content/23/4/493.full.html\#ref-list-1

Creative This article is distributed exclusively by the RNA Society for the first 12 months after the Commons

License full-issue publication date (see http://rnajournal.cshlp.org/site/misc/terms.xhtml). After 12 months, it is available under a Creative Commons License (Attribution-NonCommercial 4.0 International), as described at http://creativecommons.org/licenses/by-nc/4.0/.
Email Alerting Receive free email alerts when new articles cite this article - sign up in the box at the Service top right corner of the article or click here.

To subscribe to $R N A$ go to:

http://rnajournal.cshlp.org/subscriptions 